\title{
Research Paper \\ Investigating and comparing the behavioral and emotional problems of students using grade skipping with normal students
}

\begin{abstract}
Citation: Motamedi Z, Afrooz Gh.A, Arjmandnia A.A. Investigating and comparing the behavioral and emotional problems of students using grade skipping with normal students. J of Psychological Science. 2022; 20(107): 2045-2058.
\end{abstract}

Zohreh Motamedi ${ }^{1}$, GholamAli Afrooz ${ }^{2}$, AliAkbar Arjmandnia ${ }^{3}$

1. Ph.D Candidate, Department of Psychology and Education of Exceptional Children, Science and Research Branch, Islamic Azad University, Tehran, Iran.

2. Distinguished Professor, University of Tehran,Tehran, Iran.

3. Associate Professor, Department of psychology and Education for Exceptional Children, Faculty of Psychology and Education, University of Tehran, Tehran, Iran.

URL: https://psychologicalscience.ir/article-1-1044-fa.html
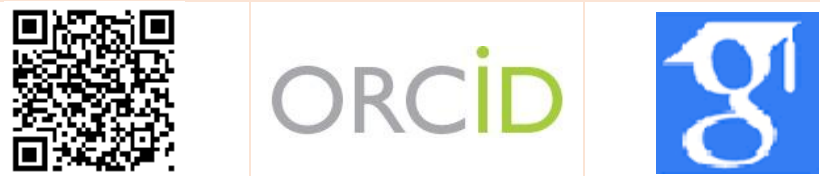

$\underline{10.52547 / J P S .20 .106 .2045}$

\section{A R T I C L I N F O A B S T R C T}

Keywords:

Behavioral - emotional problems, grade skipping, students
Background: The oldest method of educating gifted students is grade skipping. In this case, gifted students are able to complete the academic years of the regular education system more quickly and graduate one or more years earlier. According to the report of the Exceptional Education Organization of Iran, the demand for grade skipping is $70 \%$ higher than the international standards, and it is increasing every year, but still a study that has dealt with the behavioral and emotional problems of students using this plan has been neglected.

Aims: The purpose of this research is to compare and study the behavioral and emotional problems of students using grade skipping with other students.

Methods: This descriptive study was a causal-comparative study. The statistical population includes students using the grade skipping in the academic year 2019-2020 in Khorasan Razavi province that 165 out of 286 grade-skipped students were selected by regular random sampling method and the peer group (384 people) as a control group from normal grade students by multi-stage cluster sampling method. To collect the data, a child strength and weakness questionnaire (Goodman, 1997) was used and data analysis was performed with one-way analysis of variance, Scheffe post hoc test, Pearson correlation test and simultaneous multivariate regression.

Results: In this study, findings showed that emotional-behavioral problems in all subscales (Conduct disorder, emotional symptoms, communication problems or peer problems) were higher in students who used grade skipping compared to other peer students $(\mathrm{P}<0 / 05)$.

Conclusion: Students who used the academic leap and had a lower calendar age than their classmates showed more behavioral and emotional problems. It is suggested to use methods based on enriching the educational content in educating gifted students.

* Corresponding Author: GholamAli Afrooz, Distinguished Professor, University of Tehran,Tehran, Iran.

E-mail: afrooz@ut.ac.ir

Tel: (+98) 9121113929

2476-5740/ (C) 2021 The Authors. This is an open access article under the CC BY-NC-ND license

(https://creativecommons.org/licenses/by-nc/4.0/). 


\section{Extended Abstract}

\section{Introduction}

Grade skipping is an educational strategy for gifted students. In Iran, one-level Grade skipping (first to third, second to fourth, third to fifth, and fourth to sixth) and Grade skipping for the second time in elementary school in the provinces are carried out under the direct supervision of the Exceptional Education Organization. Skipping two or more grades is also possible by observing the relevant regulations. Relevant documents must be approved by the Special Commission of the Higher Education Council and intelligence qualification by the Exceptional Education Organization (Kazemihaghighi, N. 2015).

Gifted students have certain characteristics. Because of their differences with other children and adolescents in terms of health in their areas of social and emotional development, or the lack of coordination or incoherence between social, emotional, and cognitive development, they may be at greater risk (Gallagher, S., Smith, S., \& Merrotsy, P. 2013). Some new information and research also show that, contrary to previous perceptions and theories, students and people with higher than average IQ also have behavioral and emotional problems. In some cases, the prevalence of disorders in these children and adolescents is higher than average (Agajani, S., Narimani, M., \& Ariapooran, S. 2011). On the other hand, having a gifted label can create dysfunctional cognitions in gifted teenagers and lead to negative feelings and experiences. This label can create excessive and unrealistic expectations in parents, teachers, and friends and lead to negative perfectionism in children. Some experts also believe that these people are more likely to have more emotional and psychological problems than normal people, especially in adolescence and adulthood, because they are more sensitive to interpersonal conflicts due to their cognitive abilities and experience more feelings of alienation and tension (Shek, D. T., \& Lin, L. 2016).

Sayler \& Brookshire (1993) conducted a study comparing the social, emotional, and behavioral adjustment of gifted and normal eighth-grade students in three educational situations. These three educational situations included the early start of school by gifted students, the presence of gifted students in special classes, and the presence of gifted students in regular schools. The findings show that students who grew up in the first and second type of educational environments had a better perception of their social and emotional development and showed fewer behavioral problems than students in normal educational environments.

The unfortunate fact that is being observed now is that some families, based on unreliable criteria, think that their children are gifted and force them to finish their education in a short time. Thus, regardless of the ultimate goal of educating gifted children, they harm their balanced physical and emotional development (Besharat, 2015). Every year, the number of students applying for grade skipping increases. However, very little research has evaluated the plan, examining the psychological status or problems faced by students using the grade skipping plan. The aim of this study was to investigate and compare the behavioral and emotional issues of students admitted to the grade skipping plan with other students. The general question of the research: "Is there a significant difference between the rate of behavioral-emotional problems (emotional problems, Conduct Disorder (CD), and communication problems with peers) of students using grade skipping and normal students?"

\section{Method}

The present study is descriptive and causalcomparative. The statistical population of this study includes all primary school students in Khorasan Razavi province who used the grade skipping plan in the academic year 2019-2020 and the number of these students was 286. The sample size according to the Cochran formula was 165 people. It was selected by regular random sampling method. The number of normal students in the desired grades (third, fourth, fifth, and sixth) was 480968, of which 384 were selected by cluster random sampling. Necessary data were collected. Then the results were analyzed by one-way analysis of variance (ANOVA), Scheffe post hoc test, Pearson correlation test, and multivariate regression. In order to investigate the differences between the groups by modulating the effects of pre- 


\section{Monthly Journal of Psychological Science}

Vol. 20, No. 107, Winter(February) 2022 test scores, SPSS software version 23 was used. Research tools include the Problem and Strengths Questionnaire developed by Goodman in the UK in 1997 based on the ICS-10 diagnostic criteria and used for ages 3-16. Checking the accuracy and reliability of the questionnaire also shows the reliability of the questionnaire. To assess the internal reliability of the SDQ, Goodman (2001) reported Cronbach's alpha of 0.73 for various scales, a figure that has been repeated in other studies in the same range. Cronbach's standard alpha coefficient was used to calculate the reliability of the child's strengths and weaknesses questionnaire. Cronbach's alpha coefficient in the components of emotional-behavioral problems, emotional problems, Conduct Disorder (CD), and communication problems with peers was $0.91,0.92$, 0.88 , and 0.86 , respectively.

\section{Results}

Out of 286 students using the grade skipping, 73 were girls $(45 \%)$ and 90 were boys $(55 \%)$. The frequency in different educational levels is as follows: third grade 16 people (10\%), fourth grade 111 people (67\%), fifth grade 20 people (12\%), and sixth grade 18 people $(11 \%)$.

Table 1. Analysis of variance in MANCOVA to compare emotional behavioral problems and its dimensions based on research groups

\begin{tabular}{ccccccc}
\hline test & amount & $\mathrm{F}$ & $\begin{array}{c}\text { Degree of error } \\
\text { freedom }\end{array}$ & $\begin{array}{c}\text { The significance } \\
\text { level }\end{array}$ & trace size & $\begin{array}{c}\text { Statistical } \\
\text { power }\end{array}$ \\
\hline Pillai trace & $0 / 05$ & $6 / 94$ & 6 & $0 / 001$ & $0 / 05$ & 1 \\
Wilks lambada & $0 / 94$ & $6 / 94$ & 6 & $0 / 001$ & $0 / 05$ & 1 \\
Hoteling's trace & $0 / 06$ & $6 / 94$ & 6 & $0 / 001$ & $0 / 05$ & 1 \\
Roy's Largest Root & $0 / 06$ & $6 / 94$ & 6 & $0 / 001$ & $0 / 05$ & 1 \\
\hline
\end{tabular}

A s can be seen in Table 1, the significance level in the tests of Pillai trace, Wilks lambada, Hotelling's trace, and Roy's Largest Root is significant at the level of $0.01(\mathrm{P}<0.01)$. Therefore, it can be inferred that there is a difference between research groups (gifted and normal students) in terms of emotional- behavioral problems and their dimensions. According to the amount of effect size, it can be said that 0.05 of the difference between normal and gifted students is related to emotional-behavioral problems and their dimensions. Statistical power equal to 1 indicates the adequacy of the sample.

Table 2. Results of one-way analysis of variance to compare emotional behavioral problems and its dimensions based on research groups

\begin{tabular}{ccccccccc}
\hline Variables & DF & F & $\begin{array}{c}\text { Average } \\
\text { squares }\end{array}$ & $\begin{array}{c}\text { The significance } \\
\text { level }\end{array}$ & $\begin{array}{c}\text { trace } \\
\text { size }\end{array}$ & $\begin{array}{c}\text { Statistical } \\
\text { power }\end{array}$ & $\begin{array}{c}\text { lower } \\
\text { limit }\end{array}$ & $\begin{array}{c}\text { upper } \\
\text { limit }\end{array}$ \\
\hline Emotional Behavioral & 1 & $23 / 98$ & $991 / 1$ & $0 / 001$ & $0 / 003$ & 1 & $0 / 03$ & $3 / 44$ \\
$\quad \begin{array}{c}\text { Problems } \\
\text { Emotional symptoms }\end{array}$ & 1 & $5 / 16$ & $14 / 94$ & $0 / 023$ & $0 / 008$ & $0 / 7$ & $0 / 04$ & $0 / 56$ \\
Conduct Disorder (CD) & 1 & $5 / 67$ & $11 / 37$ & $0 / 017$ & $0 / 008$ & $0 / 7$ & $0 / 04$ & $0 / 48$ \\
Problem with peers & 1 & $4 / 2$ & $8 / 95$ & $0 / 041$ & $0 / 006$ & $0 / 6$ & $0 / 01$ & $0 / 45$ \\
\hline
\end{tabular}

As can be seen in Table 2, emotional-behavioral problems are significant at the 0.01 level $(\mathrm{P}<0.01)$. The value of $\mathrm{F}$ is equal to 23.98 and is greater than the value of $4(\mathrm{~F}<4)$. The distance between the lower limit (0.03) and the upper limit (3.44) does not include the number zero (0). Therefore it can be inferred with $99 \%$ confidence that emotionalbehavioral problems between gifted and normal students are different. Given the size of the trace, 0.03 of the difference between normal and gifted students is related to emotional-behavioral problems. Statistical power equal to 1 indicates the adequacy of the sample. According to the results of analysis of variance in MANCOVA to compare emotionalbehavioral problems, its dimensions based on research groups, and the results of one-way analysis of variance to compare emotional-behavioral problems, it can be inferred with $99 \%$ confidence, there is a significant difference in emotional behavioral problems among normal and gifted students. According to the level of confidence, it can be said that the result is statistically significant and the rate of behavioral-emotional problems of students using the grade skipping is higher. 
The aim of this study was to investigate and compare the behavioral and emotional problems of students using grade skipping with normal students. According to the results of analysis of variance in MANCOVA to compare emotional-behavioral problems, its dimensions based on research groups, and the results of one-way analysis of variance to compare emotional-behavioral problems, it can be inferred with 99\% confidence, there is a significant difference in emotional behavioral problems among normal and gifted students. According to the level of confidence, it can be said that the result is statistically significant and the rate of behavioral-emotional problems of students using the grade skipping is higher.

\section{Conclusion}

Taking a look at the statistics of countries with more advanced education systems, we see that only about $0.05 \%$ of all German students have used grade skipping. Even among a select sample of highly intelligent students in the United States ( 0.01 percent of the total student population), only $8 \%$ used grade skipping in high school (Park, G., Lubinski, D., \& Benbow, C. P. 2013). Meanwhile, according to the statistics of the Exceptional Education Organization of Iran (2014), annually more than 5\% of primary school students apply for grade skipping. This statistic is increasing every year. One of the reasons for this increase is the parents with high demands. In fact, parents, regardless of the wishes of their children and their educators, decide to do this to satisfy their desires and aspirations. (Talaei, Hassanabadi, Baraparpour, Seyed Mirzaei Jahaghi and Banshi, 2018).

\section{Ethical Considerations}

Compliance with ethical guidelines: The authors extracted this article from the $\mathrm{PhD}$ dissertation of the first author in the Department of psychology and Education for Exceptional ChildrenEthical considerations of this study with grant number 100093 approved by the Research Council of Islamic Azad University, Science and Research Branch of Tehran.

Funding: This study was conducted as a PhD thesis with no financial support.

Authors' contribution: The first author was the senior author, the second were the supervisors and the.

Conflict of interest: the authors declare no conflict of interest for this study.

Acknowledgments: I would like to appreciate the supervisor, the advisors, the participants, Also, my colleagues in exceptional education in Khorasan Razavi province, who helped in this research. 


\section{بروسى و مقايسه مشكلات رفتارى و هيجانى دانش آموزان استفاده كننده از جهش تحصيلى با دانش آموزان عادى}

\section{زهره معتمدى '، غلامعلى افروز "'، على اكبر ارجمندنيا"}

ا. دانشجوى دكترى روانشناسى و آموزش كود كان استثنايى، واحد علوم و تحقيقات، دانشكاه آزاد اسلامى، تهران، ايران.

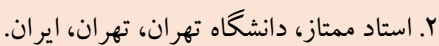

r. دانشيار، گروه روانشناسى و آموزش كود كان استثنايى، دانشكده روانشناسى و علوم ترييتى، دانشكاه تهران، تهران، ايران.

زمينه: قديمىترين روش در آموزشويرورش دانش آموزان تيزهوش، جهش تحصيلى است. بهنحوى كه دانش آموزان مستعد قادرند سالهاى

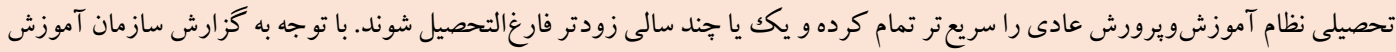

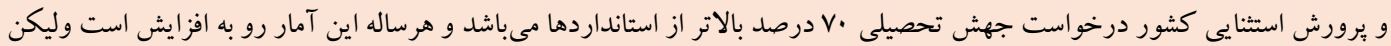
بالين حال يُوهشى كه به مشكلات رفتارى و هيجانى دانش آموزان استفاده كننده از اين طرح يرداخته باشد مغفول مانده است.

هدف: مقايسه و بررسى مشكلات رفتارى و هيجانى دانش آموزان استفاده كننده از جهش تحصيلى با ديكر دانش آموزان بوده است. روش: روش ئوهش حاضر توصيفى از نوع على - مقايسهاى است. جامعه آمارى شامل دانش آموزان استفاده كننده از طرح جهش در سال تحصيلى

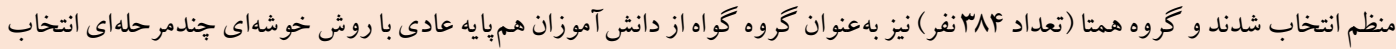

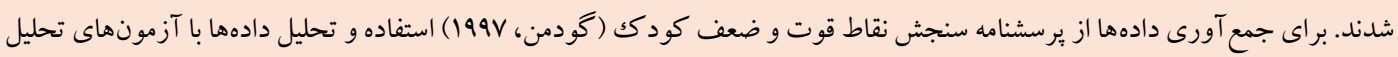
واريانس يككراهه، آزمون تعقيبى شفه، آزمون همبستخى ييرسون و ركر سيون جند متغيره همزمان انجام يذيرفت. يافته ها: نتايج نشان داد كه مشكلات رفتارى هيجانى در همه خردهمقياسها (اختلال رفتار هنجارى، نشانگان هيجانى، مشكلات ارتباطى يا

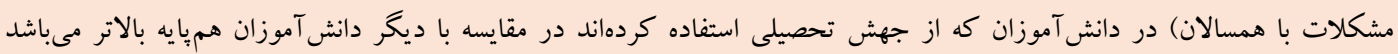
$(\mathrm{P}<\cdot / \cdot \Delta)$ نتيجه كيرى: دانش آموزانى كه از جهش تحصيلى استفاده كرده بودند و سن تقويمى بايينترى نسبت به همكلاسى هاى خود داشتند

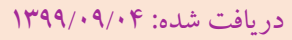

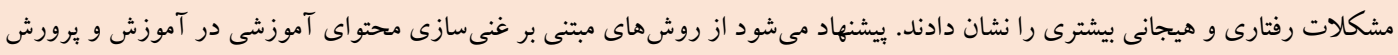


طرد مى كنند و درنتيجه فرصتهاى آموزشى آنان كاهش مىيابد (تكلوى،

. (1)q.

جنابادى، يورقاز و شعبانى (94) دور نتايج يزوهش "بررسى مقايسهاى

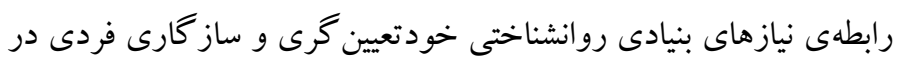

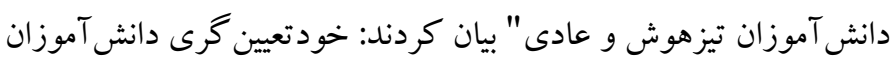

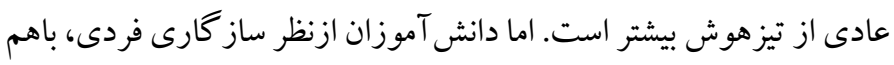

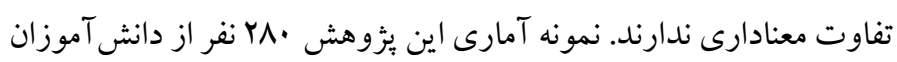
تيزهوش و عادى مدارس شهر زاهدان بودند.

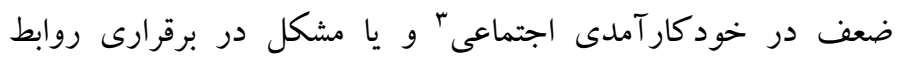

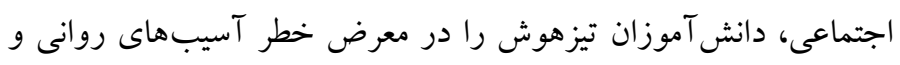

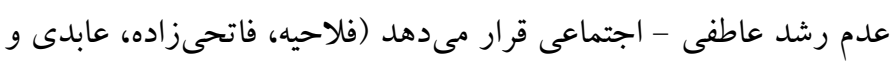

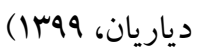

از سوى ديخر داشتن بر هسب تيز هوش مى تواند شناخت هاى ناكار آمدى

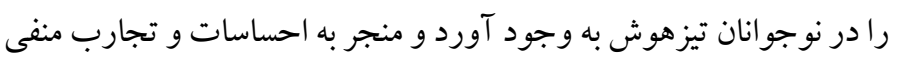
شود. اين برجسب مى تواند انتظارات بيشازحد و غيرواقع بينانهاى را در

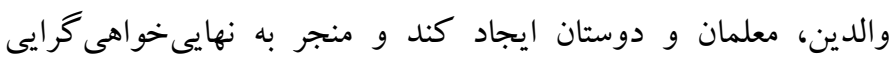

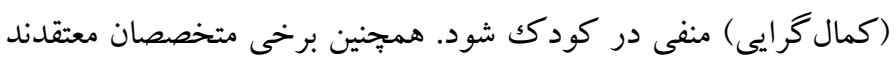

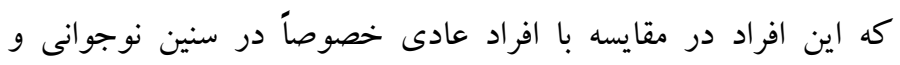
بزر گسالى احتمالاً داراى مشكلات عاطفى و روانشناختى بيشترى مىباشند،

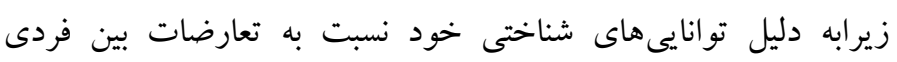

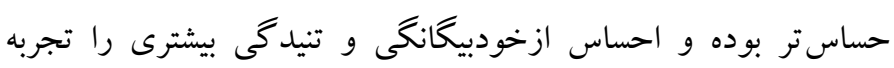

مى كنند (شك و لين، 19. (Y)

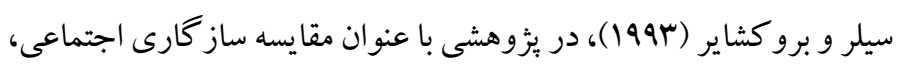

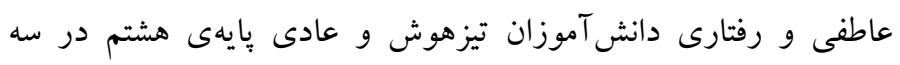

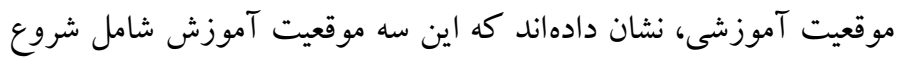
زودتر مدرسه توسط دانش آموزان تيزهوش، حضور دانش آموز تيزهوش

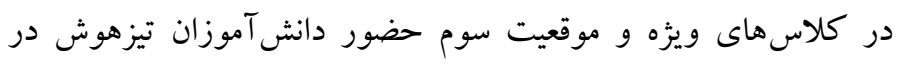
مدارس عادى بوده است. يافتهاى بهدست آمده نشان مىدهد كه دون دانش

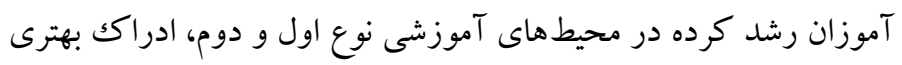

${ }^{3}$. Social self-efficacy
مقلفمه جهش تحصيلى'، يكك راهبرد آموزشى براى دانش آموزان تيزهوش 'است.

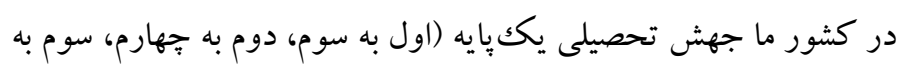

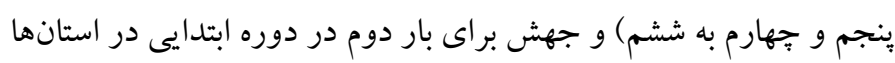
تحت نظارت مستقيم سازمان آموزش و وبرورش استثنايى كشور انجام

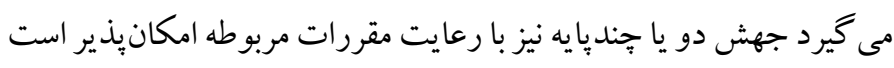

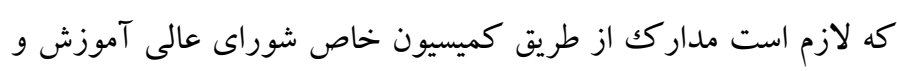
يرورش و صلاحيت هوشى توسط سازمان آموزش و يرورش استثنايى تأييد كردد (كاظمى حقيقى، سوبا1).

دانش آموزان تيزهوش داراى ويزگى هاى خاصى خاصى هستند كه به به دليل

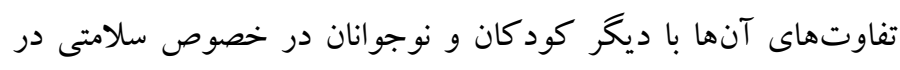
حوزههاى رشد اجتماعى و هيجانى خود و يا عدم هماهنكى يا عدم انسجام

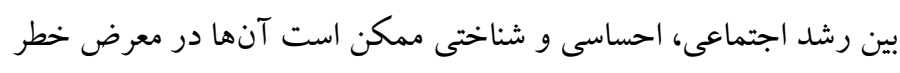

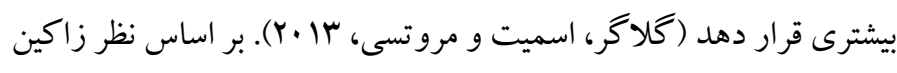

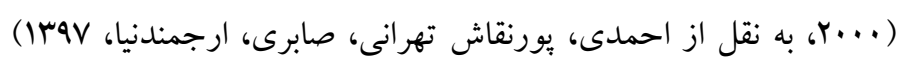

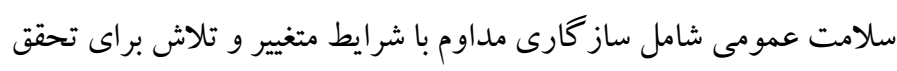

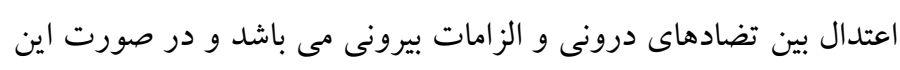
اعتدال، مشكلات فرد كاهش مى يابد.

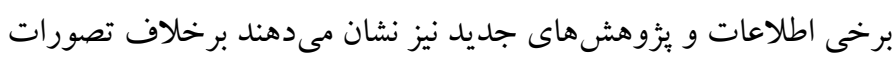

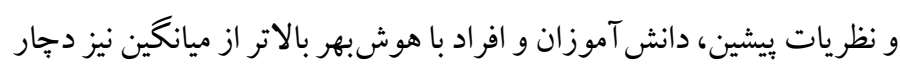

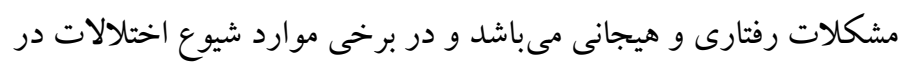

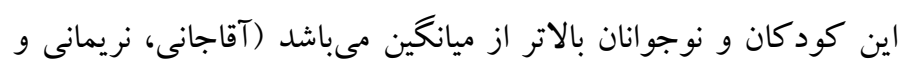

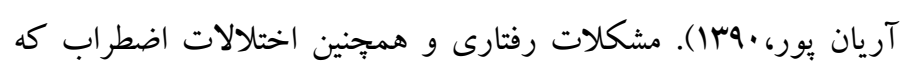
يكى از شايع ترين اختلال هاى روانيزشكى در همهى كود كان و نوجوانان

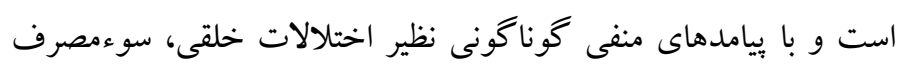

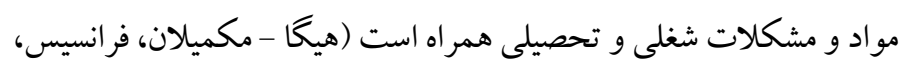

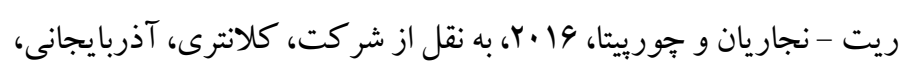

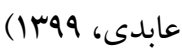

اغلب كود كان و نوجوانان با مشكلات رفتارى احساسات منفى دارند و با

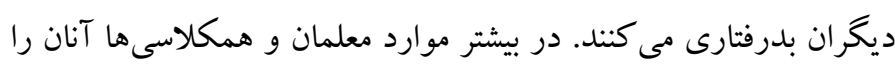

1. Grade skipping

2. Gifted 
و مقايسه مسائل رفتارى و هيجانى دانش آموزان يذيرفته شده در طرح

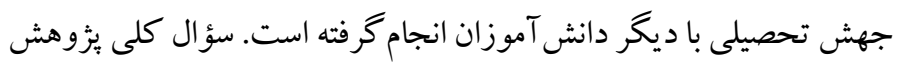
اين است كه "آيا بين ميز ان مشكلات رفتارى - هيجانى (مشكلات عاطفى، دانس،

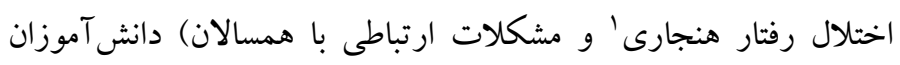

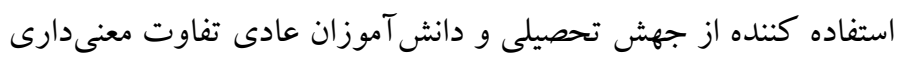

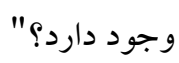

روش

الف) طرح يُووهش و شر كت كنند كان: يُزوهشِ حاضر، توصيفى از نوع على - مقايسهاى است. جامعه آمارى اين بثزوهش شامل تمامى دانش

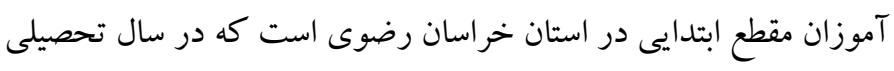
 نفر بوده است، حجم نمونه بر اساس فرمول كوكران 190 نفر تعيين و با تصني

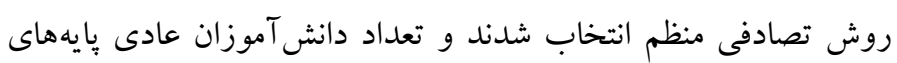

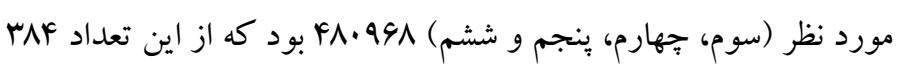

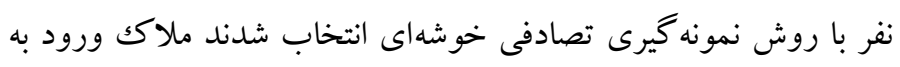

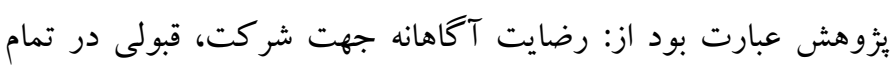
مراحل جهش تحصيلى اداره آموزش و برورش استثنايى استان و تحصيل

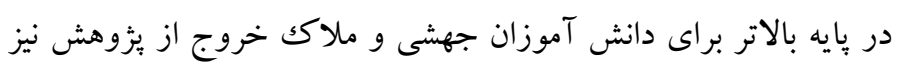

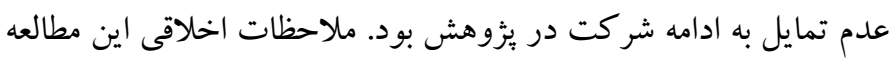
مصوب شوراى بثزوش دانشگاه آزاد اسلامى واحد علوم تحقيقات تهر ان

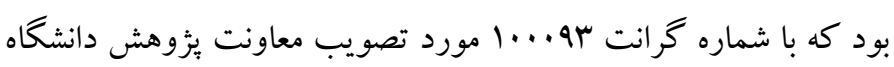

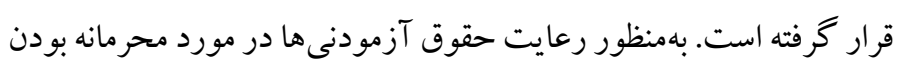

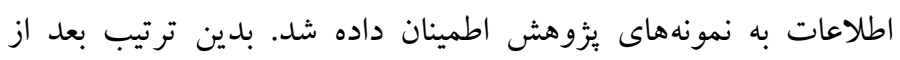

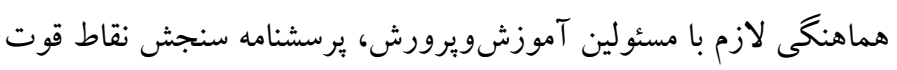

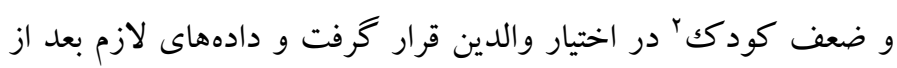

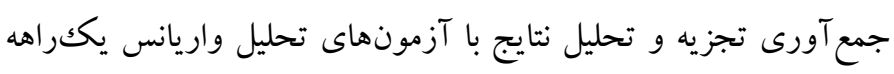

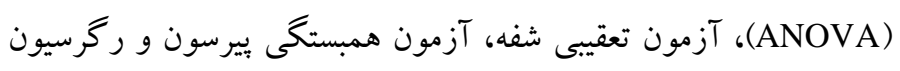

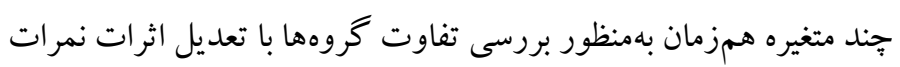

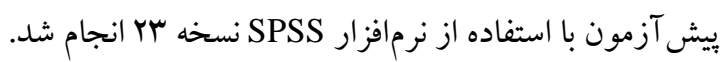

2. Strengths and Difficulties Questionnaire (SDQ)
از رشد اجتماعى و عاطفى خود داشتهاند و مشكلات رفتارى كمترى از دانش آموزان در محيطهاى آموزشى عادى نشان دادهاند.

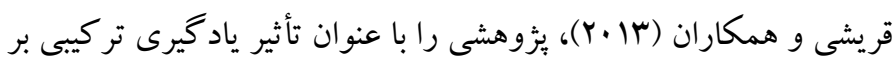
هوش هيجانى، حرمت خود و بيشرفت تحصيلى در جهش كلاسى دانش

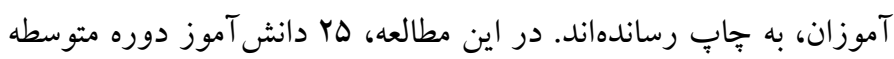
واجد شرايط براى جهش تحصيلى بهطور تصادفى انتخابشدهاند. سيس

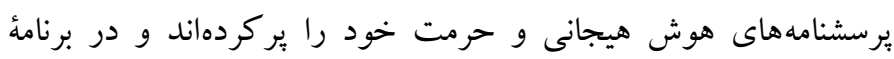

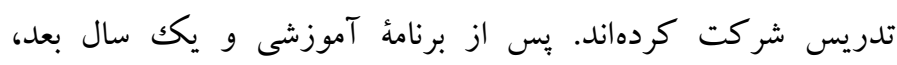

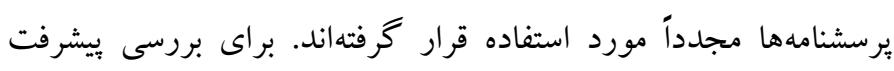

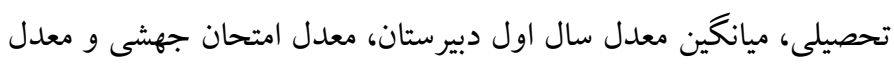

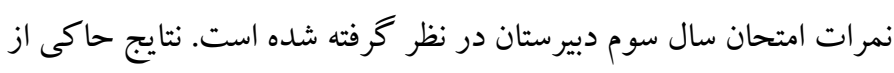
افزايش معنادار هوش هيجانى و حرمت خود در دانش آموزان است.

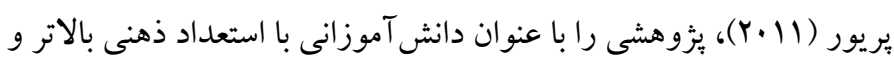

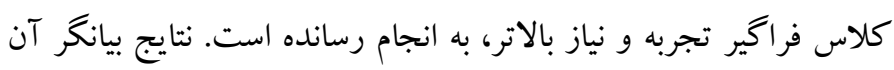

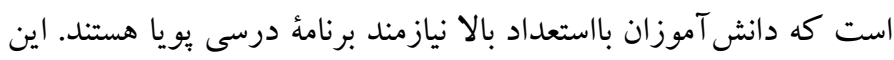

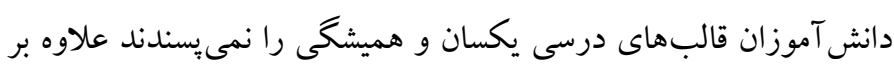
برنامُٔ درسى همجنين جو كلاس درسى نيز اهميت دارد و بيان مى كند در

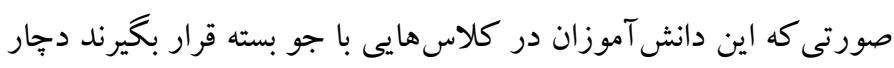

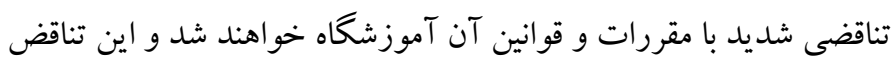

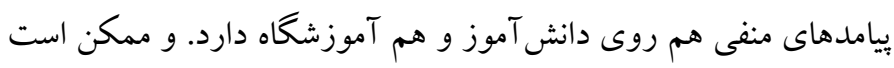
باعث ايجاد يا تشديد مشكلات هيجانى يا رفتارى در دانش آموزان گردمد دود.

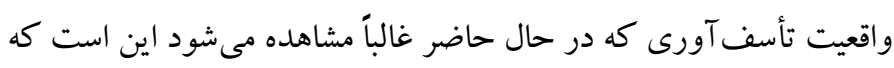
برخى از خانو ادهها گاهى بر اساس ضو ابط غير إبل

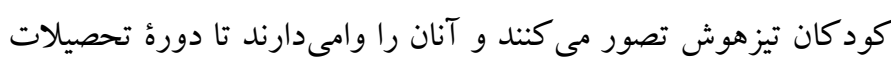

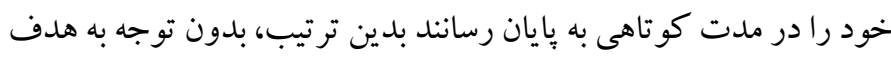

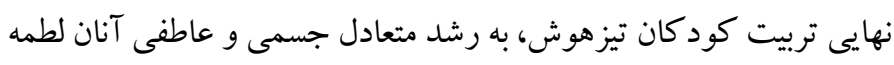

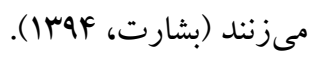

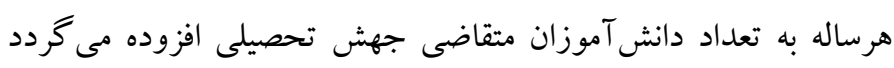

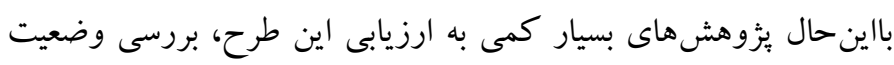

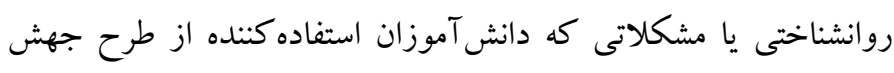

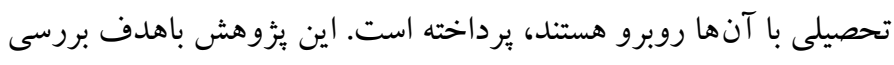

1. Conduct Disorder (CD) 
هاى 19 تا · r مر بوط به مؤلفهى "مشكلات ارتباطى با همسالان" است؛ در

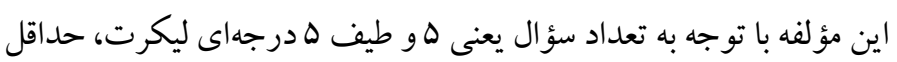

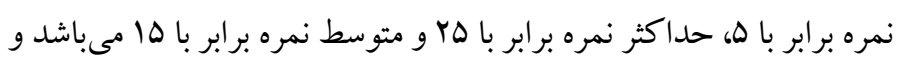

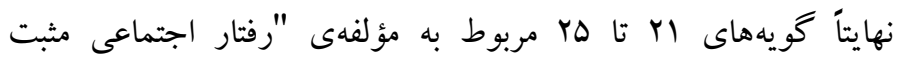

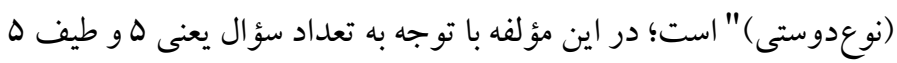

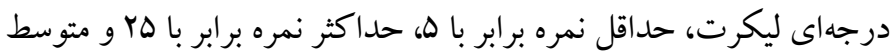
نمره برابر با ها است.

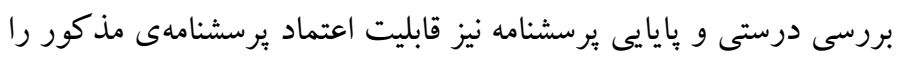

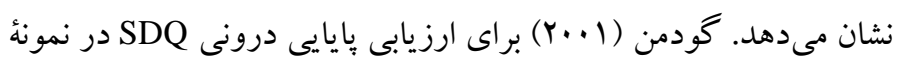

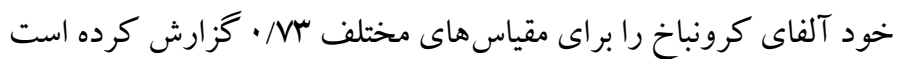
كه اين رقم در ساير مطالعات نيز در محدودهُ مشابه تكرار شده است.

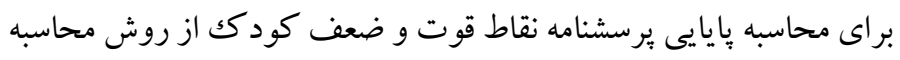

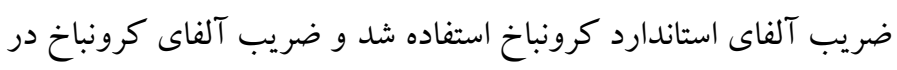
مؤلفههاى مشكلات عاطفى - رفتارى، مشكلات عاطفى، اختلال رفتار

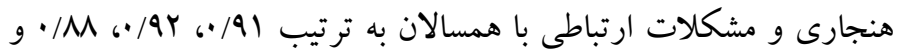
1/4 • به دست آمده است.

يافته ها

خلاصه اطلاعات جمعيت شناختى شركت كنند كان به اين شرح است: از

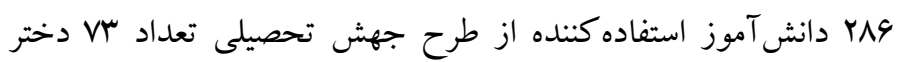

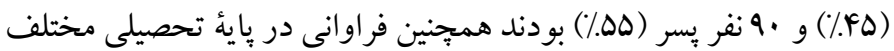

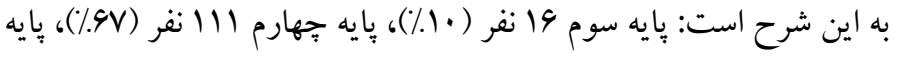

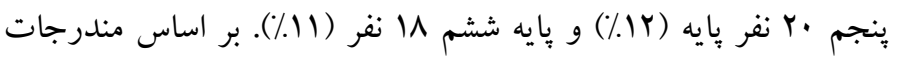

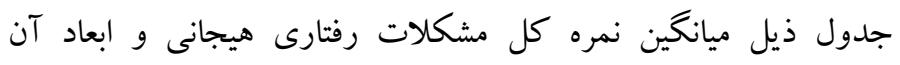

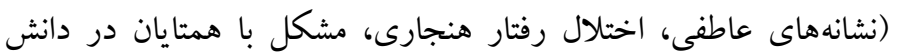
آموزان عادى به نسبت دانش آموزان جهشيافته كمتر است.
ب) (بزار برسشنامه بررسى مشكلات و نقاط قوت: اين برسشنامه در سال 1997 توسط

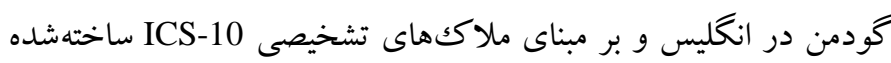

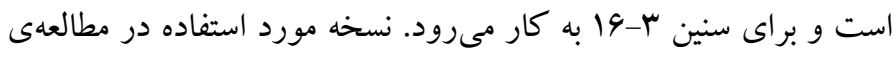

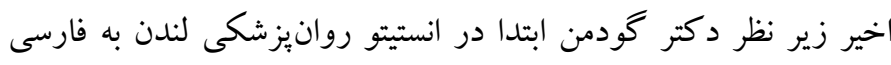

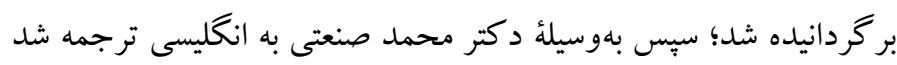

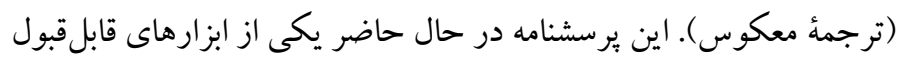

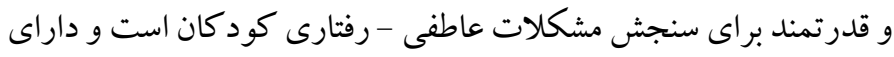

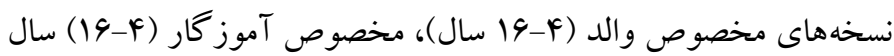

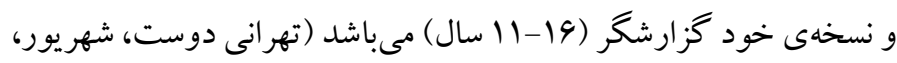
ياكباز، رضايى و احمدى، همش1).

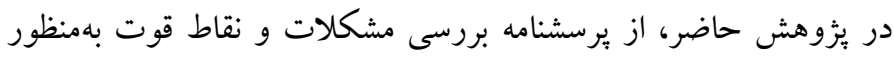

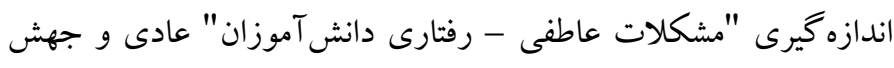

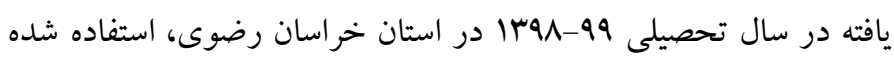

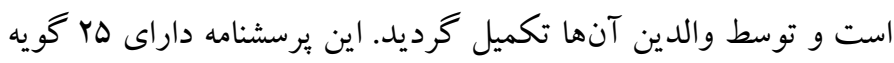

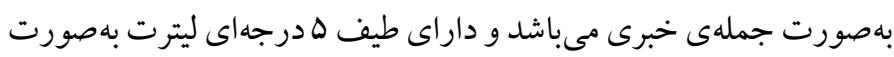

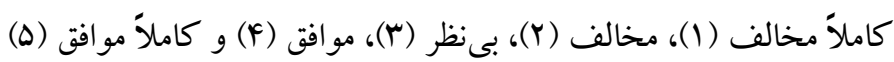

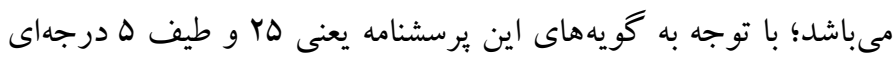

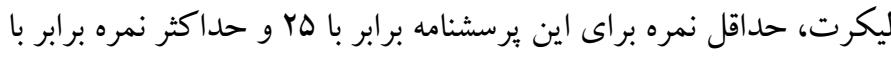

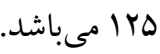
اين يرسشنامه داراى هـ مؤلفه است كه عبارتاند از: ا. مشكلات عاطفى r. اختلال رفتار هنجارى r. مشكل فزون كنشى / كمبود توجه، أ. مشكلات

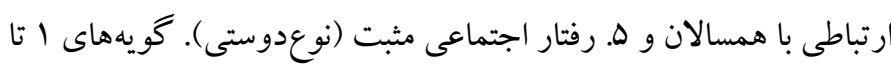

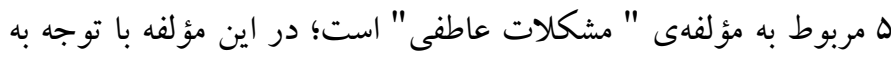

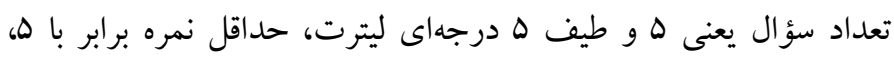

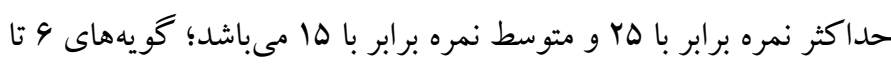

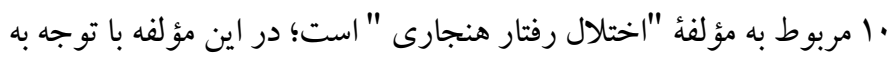

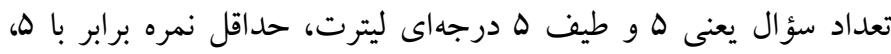

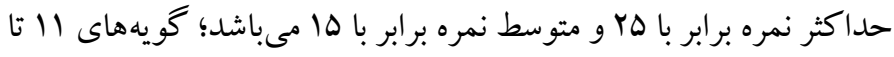

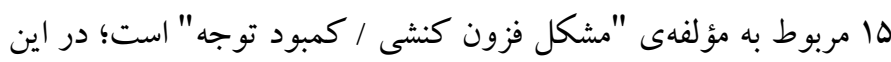
مؤلفه با توجه به تعداد سؤ ال يعنى هو طيف هد درجهاى ليترت، حداقل نمره

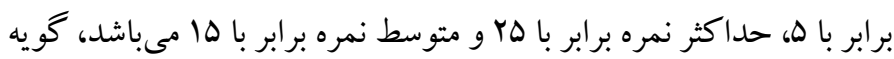




\begin{tabular}{|c|c|c|c|c|}
\hline \multicolumn{2}{|c|}{ جهش يافته } & \multicolumn{2}{|c|}{ عادى } & \multirow{2}{*}{ متغيرها } \\
\hline انحراف معيار & ميانگين & انحراف معيار & ميانگين & \\
\hline$r / r \Delta$ & $19 / 99$ & $r / \Psi \wedge$ & $\mid F / Y r$ & مشكلات - رفتارى هيجانى \\
\hline $1 / \% \Delta$ & $r / F I$ & 1/19 & $r / l l$ & نشانه هاى عاطفى \\
\hline $1 / r$ & $\mathrm{r} / 9 \mathrm{~V}$ & $1 / 0$ & $r / F 1$ & اختلال رفتار هنجارى \\
\hline $1 / r$ & $r / \Delta r$ & $1 / 9$ & $r / . q$ & مشكل با همتايان \\
\hline
\end{tabular}

بنابر اين مى توان استباط كرد كه بين گروههاى يزوهشى (دانش آموزان جهش يافته و عادى) از لحاظ مشكلات رفتارى هيجانى و ابعاد آن تفاوت

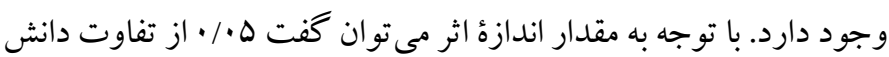
آموزان عادى و جهش يافته به مشكلات رفتارى هيجانى و ابعاد آن مربوط

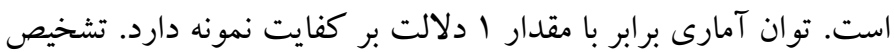

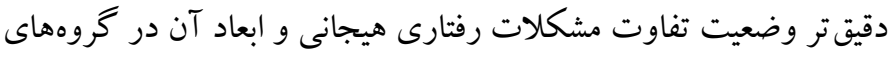

$$
\text { يُزوهشى در جدول ب ارائهشده است. }
$$

بر اساس مندرجات جدول ا ميانكين كل مشكلات رفتارى هيجانى و ابعاد

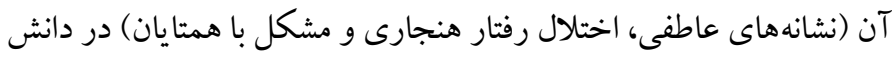

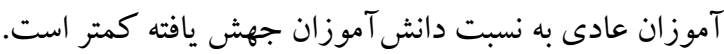
همانطور كه در جدول Y مشاهده مىشود سطح معنىدارى در آزمونهاى

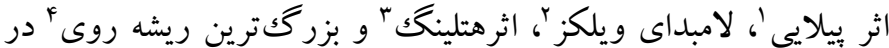

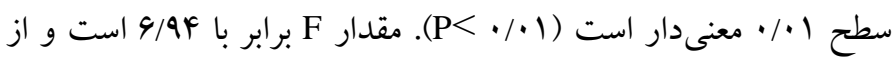
مقدار f بيشتر است (F>F).

\begin{tabular}{|c|c|c|c|c|c|c|}
\hline توان آمارى & اندازه اثر & سطح معنى دارى & درجه آزادى خطا & $\mathrm{F}$ & مقدار & آزمون \\
\hline 1 & .1 .0 &.$/ \cdot 1$ & 4 & $9 / 94$ &.$/ \cdot \Delta$ & اثر بيلايى \\
\hline 1 &.$/ . \Delta$ &.$/ \cdot 1$ & 9 & $9 / 94$ & $\cdot / 9 F$ & لامبداى وليكز \\
\hline 1 &.$/ . \Delta$ &.$/ .1$ & 4 & G/9F & .1 .9 & اثر هلتينك \\
\hline 1 & $\cdot / \cdot \Delta$ & $\cdot / \cdot .1$ & 4 & G/9F & .1 .4 & برز كترين ريشه روى \\
\hline
\end{tabular}

\begin{tabular}{|c|c|c|c|c|c|c|c|c|}
\hline جالا & حايين & $\begin{array}{l}\text { Tوارى } \\
\text { Tوان }\end{array}$ & اندازه & معنى دارى & مجيانكين & $\mathrm{F}$ & $\mathrm{DF}$ & متغيرها \\
\hline$r / F F$ & $\cdot / \cdot r$ & 1 & $\% r$ &.$\cdots 1$ & $991 / 1$ & $r r / q \Lambda$ & 1 & مشكلات رفتارى هيجانى \\
\hline$\cdot 109$ & $\cdot / r$ & $\cdot / V$ & $\% \cdot \wedge$ & 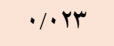 & $\mid F / 9 F$ & $\Delta / 19$ & 1 & نشانهاى عاطفى \\
\hline$\cdot / 4 \Lambda$ & $\cdot / \cdot F$ & $\cdot / V$ & $\% \cdots \wedge$ &.$/ .1 V$ & $11 / r V$ & $\Delta / 9 V$ & 1 & اختلال رفتار هنجارى \\
\hline$\cdot / F \Delta$ & $\cdot / \cdot 1$ & $\cdot 19$ & $\% / \cdot 4$ &.$/ .41$ & $\Lambda / 9 \Delta$ & $f / r$ & 1 & مشكل با همتايان \\
\hline
\end{tabular}

تفاوت دارد. با توجه به مقدار اندازه اثر مىتوان گفت س./• از تفاوت دانش آموزان عادى و جهش يافته به مشكلات رفتارى هيجانى مربوط است.

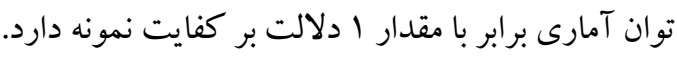

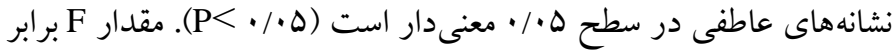

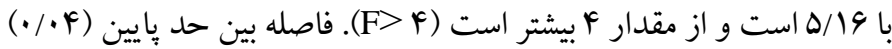

3 . hotelings trace

${ }^{4}$. Roys largest rot
همانطور كه در جدول ץ مشاهده مىشود مشكلات رفتارى هيجانى در

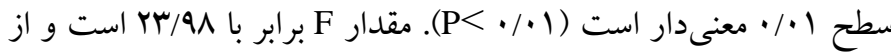

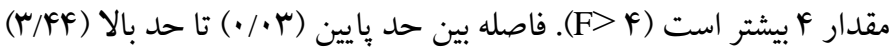

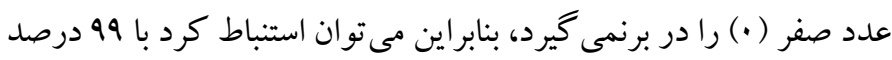
اطمينان مشكلات رفتارى هيجانى بين دانش آموزان جهشيافته و عادى

${ }^{1}$. pillai trace

2. wilks lambada 
باشند (افروز و دلير هوس1)؛ تسريع تحصيلى راهى براى سرعت بخشيدن به

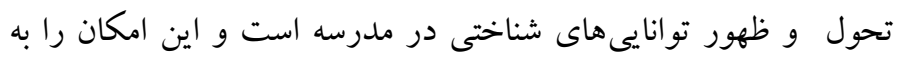

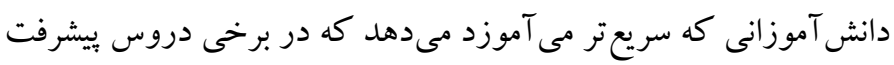

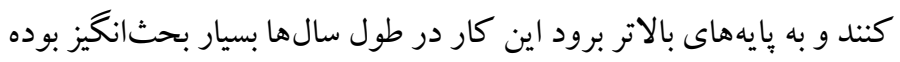

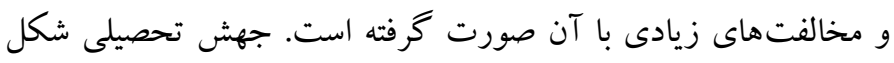
خاصى از تسريع تحصيلى است برخى متخصصان معتقدند استفاده از اين

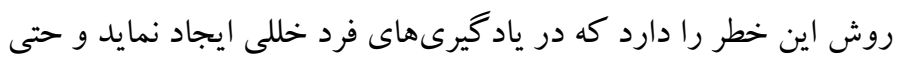

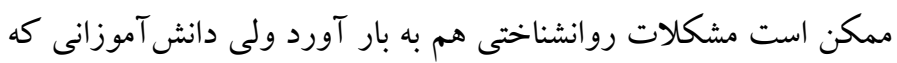
تو انايى شناختى بيشترى دارند و مشتاق بيشرفت سريعتر ازآنجه كه نظام

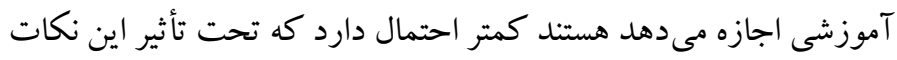

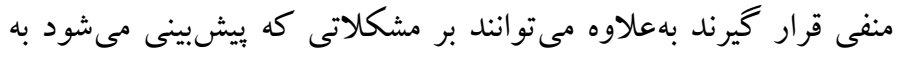
وجود آيند از طريق برنامههاى آموزشى و آمادهسازى خاص غرئ بله نمايند اين روى آورد زمانى مؤثرتر به نظر مىرسد كه تسريع تحصيلى بدون خلل

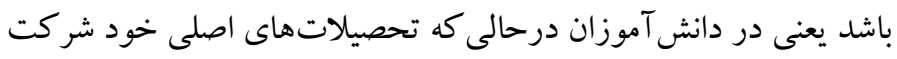

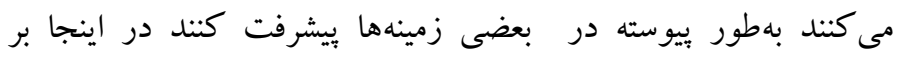

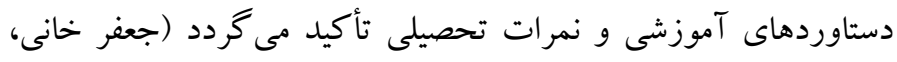

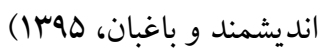

برخى يزوهشها بر روى دانشآموزان تيزهوش مانند يزوهش بيطرفان

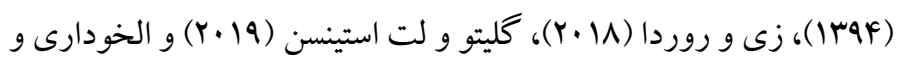
سامارا (Y) (Y) نشان دادند كه تفاوت معنادارى بين دانش آموزان تيزهوش و عادى ازنظر سازش يافتكى وجود ندارد وليكن در تحقيقات متعددى

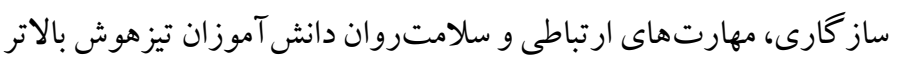
و مشكلات رفتارى و ارتباطى آنها بايين تر از دانش آموزان عادى إدى اعلام

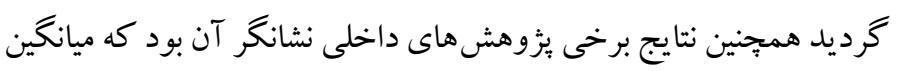
نمرات هوش هيجانى و مهارتهاى اجتماعى دانش آموزان تيزهوش بهطور

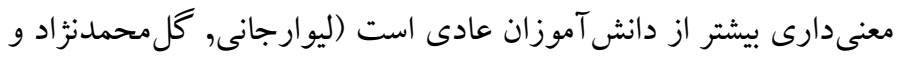

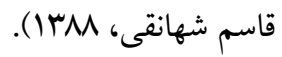

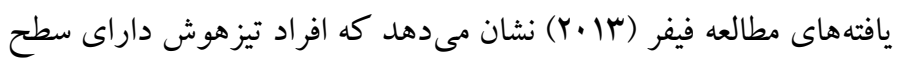
بالاترى از هوش هيجانى نسبت به همتايان غير تيزهوششان هستند و از ساز كارى هيجانى و عاطفى بالاترى برخوردارند.

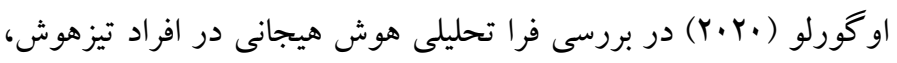

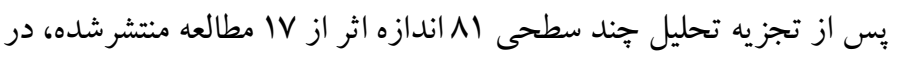

تا حد بالا (ه4ه/•) عدد صفر (•) را در برنمى گيرد، بنابراين مى توان استنباط كرد با هو درصد اطمينان نشانههاى عاطفى بين دانش آموزان جهش يافته و

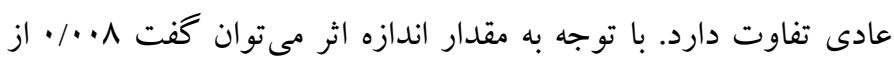
تفاوت دانش آموزان عادى و جهشيافته به نشانهاى عاطفى مربوط است. توان آمارى برابر با مقدار V/ • دلالت بر كفايت نمونه دارد.

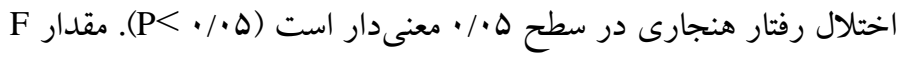

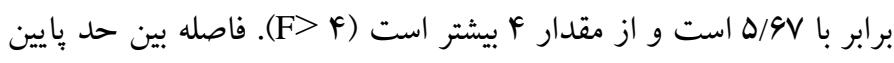
(F) استباط كرد با هه درصد اطمينان اختلال رفتار هنجارى بين دانش آموزان

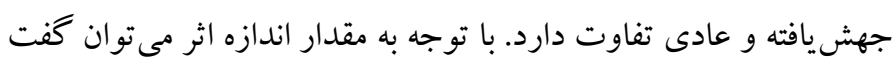

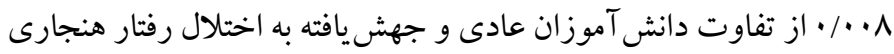
مربوط است. توان آمارى برابر با مقدار V/ • دلالت بر كفايت نمونه دارد.

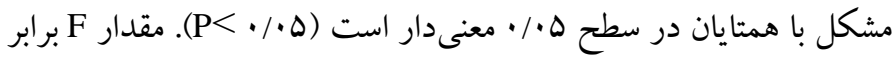

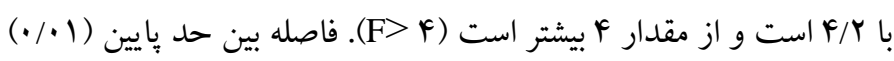

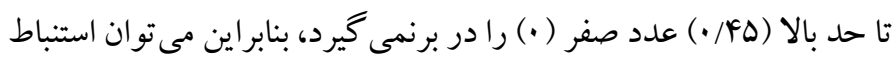

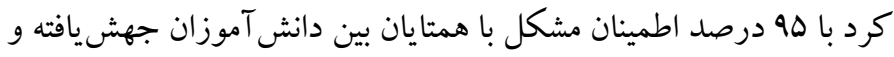

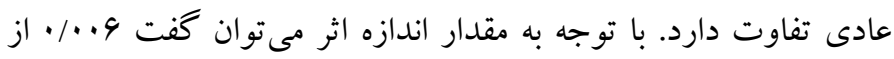
تفاوت دانش آموزان عادى و جهش يافته به مشكل با همتايان مربوط است. توان آمارى برابر با مقدار /9 • دلالت بر كفايت نمونه دارد.

\section{بحث و نتيجه كيرى}

مطالعة حاضر باهدف بر رسى و مقايسه مشكلات رفتارى و هيجانى دانش

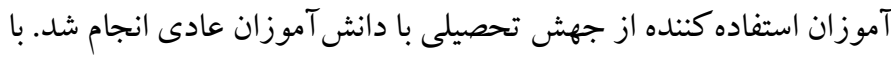

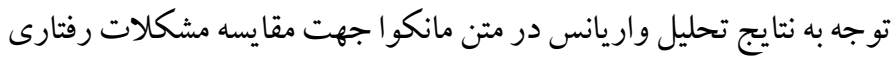

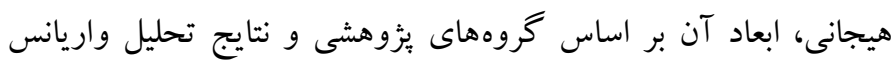
يككراهه جهت مقايسه مشكلات رفتارى هيجانى مىتوان استنباط كرد با لبان

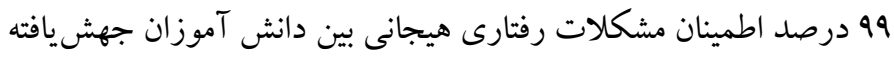

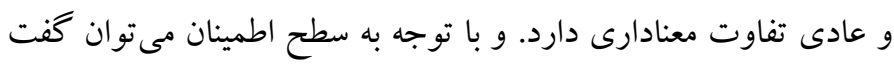

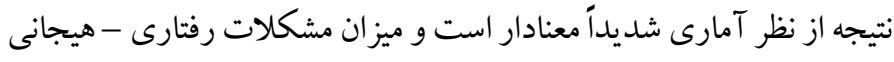
دانش آموزان استفاده كننده از جهش تحصيلى بـ بيشتر است.

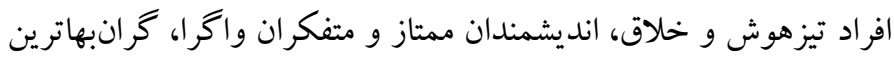

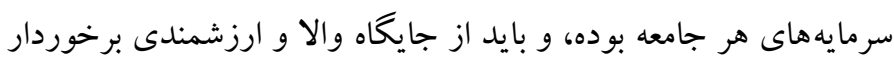


بر آورده نمودن انتظارات ديخران يا انتظار از خود در اين دانش آموزان مى تواند بسيار استرسزا باشد و عملكرد آنها را تحت تأثير قرار دهد. اغلب بزوهشهاى انجام يافته در حوزه تسريع تحصيلى مبتنى بر مقايسه

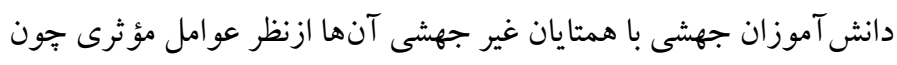

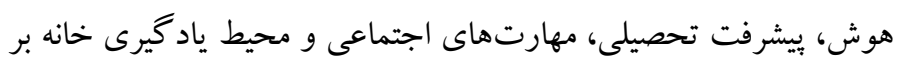

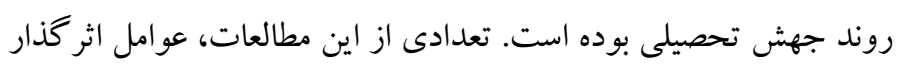

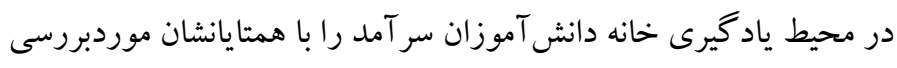

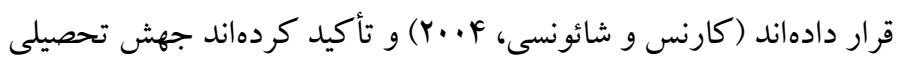
تحت تأثير محيط ياد گيرى غنى در خانه است. يكك محيط ياد نيرى غنى،

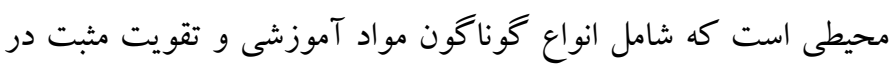
جهت اهداف تعليم و تربيت از سوى والدين براى تحول و برورش صحيح

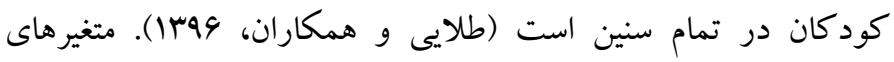

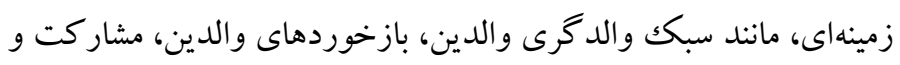
درگير شدن والدين در فعاليتهاى ياد گيرى كودكك در خانه، تحصيلات

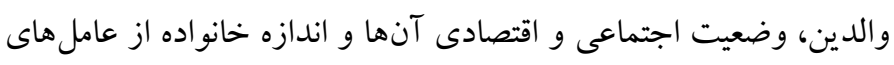

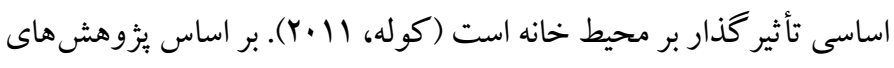
انجام يافته مشار كت و درگيرى والدين در فعاليتهاى يادگيرى كود كان

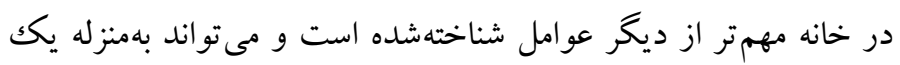

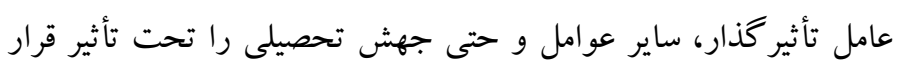

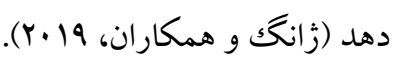

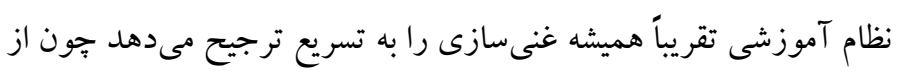

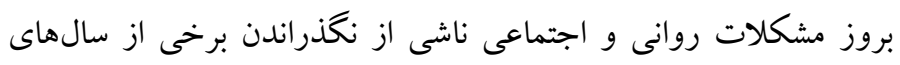

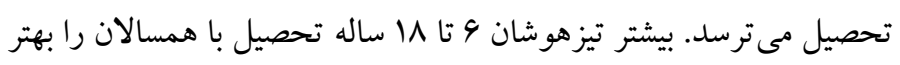

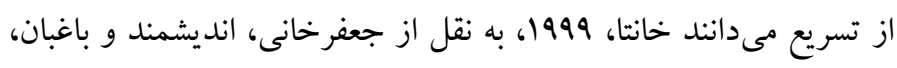

. (1)90

با در نظر گرفتن اين حقيقت كه جهش تحصيلى از نظر متخصصين علم

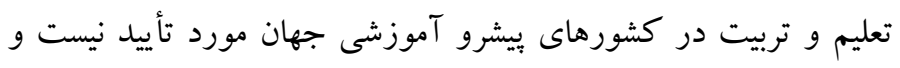

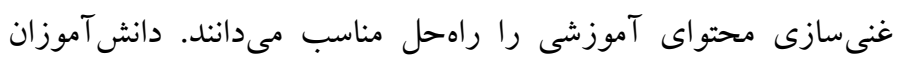
داوطلب جهش تحصيلى كه با استفاده از يك فر آيند ناقص، غربالكرى رئرى

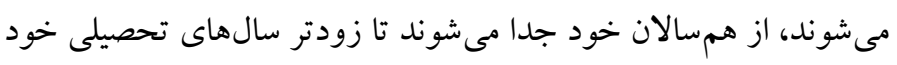
را بهويزه در دوره ابتدايى تمام كنند، و اين موضوع ظلمى به دانش دانش آموزان كشور است. در كشورهاى بيشرو به تحول متوازن اجتماعى دانش آموزان
نتايج يزوهش خويش بيان مى كند كه به نظر مىرسد افراد تيزهوش

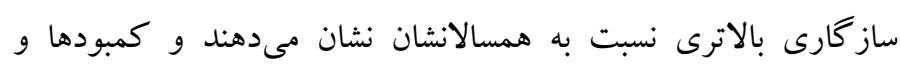
نقصهاى عاطفى و هيجانى كمترى را نيز دارند نكته قابل تأمل در دران

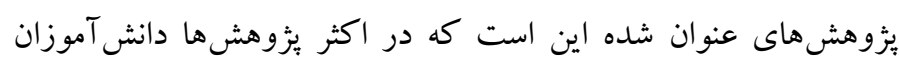
تيزهوش ساز كارى بيشترى نشان داده بودند

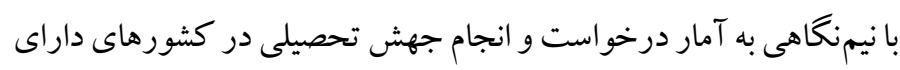

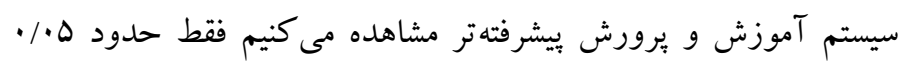

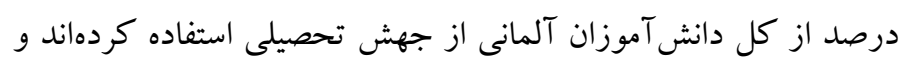

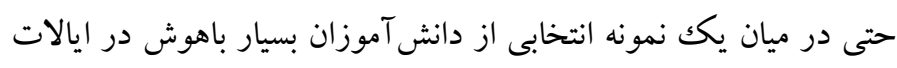

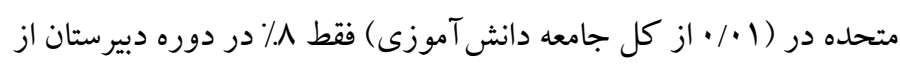

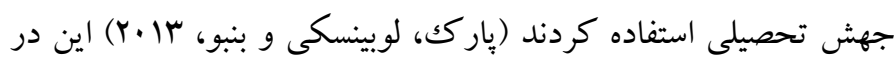
حالى ست كه آمار متقاضيان جهش تحصيلى در كشور ما طبق آمار سازمان

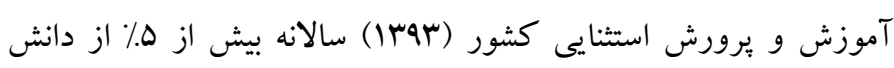

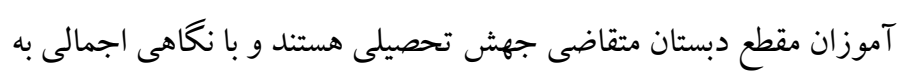

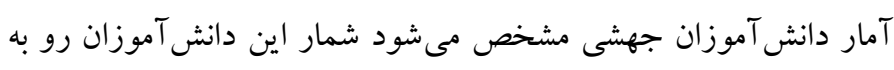

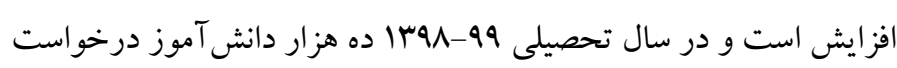
جهش داشته كه از اين آمار نصف دانش آموزان بر اساس ملاككها يذيرفته

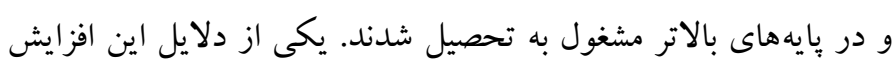

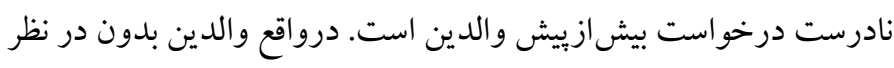

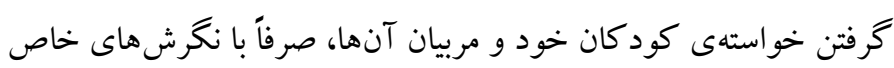

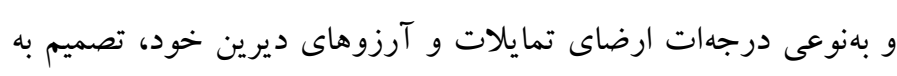
جهش تحصيلى كود كانشان مى گيرند. به نظر مىرسد والدين و نكرش

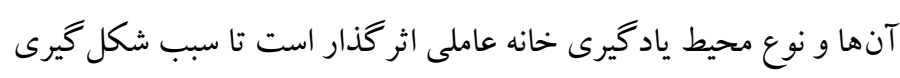
جهش تحصيلى دانشآموزان و در نهايت تمايز آنها با همتايان غير

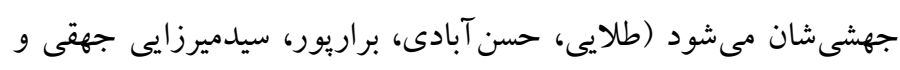

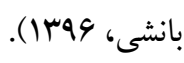

فر آيند موافقت با جهش دانش آموزان در كشور ما به گونهاى است كه

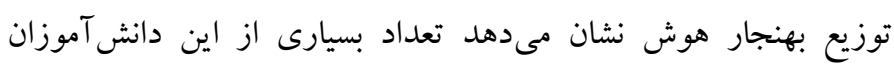

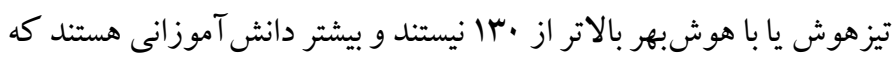

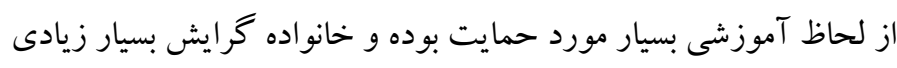

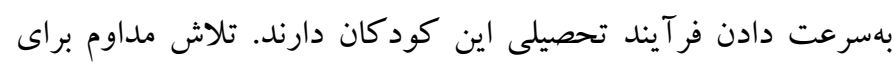


ملاحضات اخلاقى ييروى از اصول اخلاق هذوهش: اين مقاله بر خرفته از رساله دكترى نو يسنده اول در

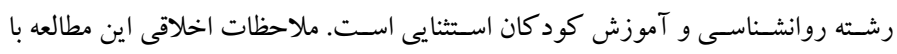

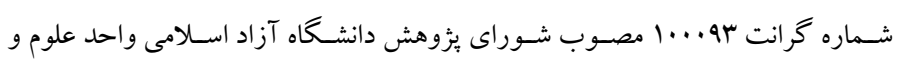
تحقيقات تهران است. حامى مالى: اين برثوهش در قالب رساله دكترى و بدون حمايت مالى مىباشد. نقش هر يكك از نويسند كان: نويسنده اول محقق اصلى اين يزوهش است. نويسنده دوم استاد راهنما و نويسنده سوم استاد مشاور رساله مىباشند.

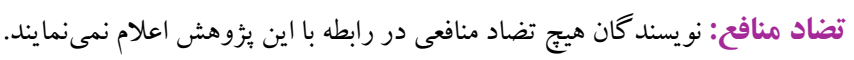
تشكر و قدروانى: بدين و سيله از اساتيد راهنما و مشاور اين تحقيق و نيز همكارانم در آموزش و برورش استثنايى استان خراسان رضوى، كه در انجام اين تحقيق يارى نمودند تشكر و قدردانى مى گردد.
توجه و زمينهاى غنى سازى محتواى آموزشى فراهم مىشود و صرفاً به آنها

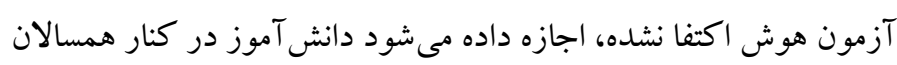

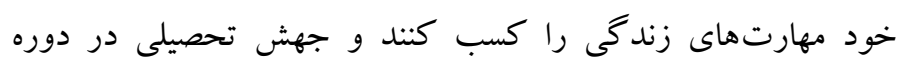

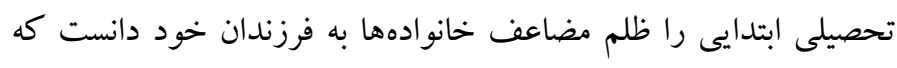

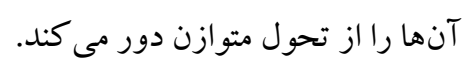

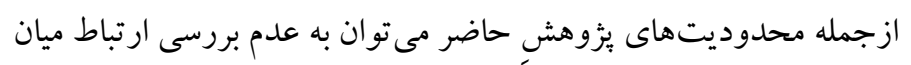

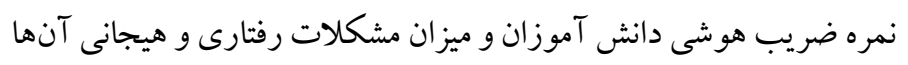

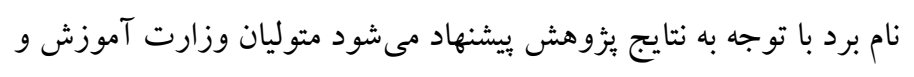

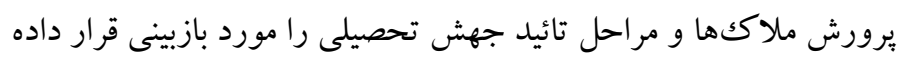

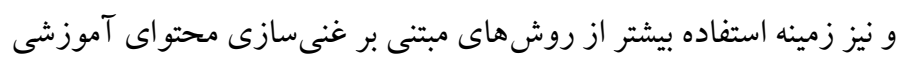

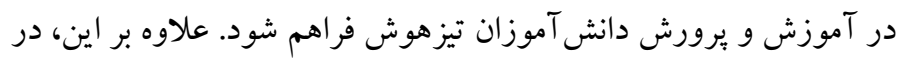

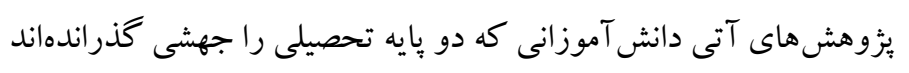
نيز به بنوان جامعه يُووهش در نظر كرفته شوند. 


\section{References}

Ahmadi, A., Poornaghash Tehrani, S. d., Saberi, M., \& Arjmandnia ,A. (2018). An investigation of Personality traits, familial state, mental health and intellectual capacity in delinquent and victimized adolescents in Tehran. The Journal of Psychological Science, 17(66), 228-245. Retrieved from. [Link]

Afrooz, D. G., \& Dalir, D. M. (2017). Perfectionism in gifted children family. Rooyesh-e-Ravanshenasi, 5(4), 47-70. Retrieved from. [Link]

Agajani, S., Narimani, M., \& Ariapooran, S. (2011). Comparing of Perfectionism and Tolerance of Ambiguity in Gifted and Non- gifted Students. Journal of Exceptional Children, 11(1), 83-90. Retrieved from. [Link]

Besharat, M. A., Mirjalili, R. S., \& Ehsan, H. B. (2015). The mediating role of meta-cognitive beliefs and cognitive emotion regulation deficit on the relationship between cognitive perfectionism and worry in generalized anxiety disorder. Journal of Fundamentals of Mental Health, 17(3), 115-122. doi:10.22038/jfmh.2015.4316. [Link]

Cole, J. (2011). A Research Review: The Importance of Families and the Home Environment. National Literacy Trust. [Link]

El-Khodary, B., \& Samara, M. (2019). The mediating role of trait emotional intelligence, prosocial behaviour, parental support and parental psychological control on the relationship between war trauma, and PTSD and depression. Journal of Research in Personality, 81, 246-256. [Link]

Fallahiyeh, s., Fatehizade, M., Abedi, A., \& Dayarian, M. (2020). The Effect of Intervention Based on Dweck's Mind Set on Academic Expectations Stress among Gifted and Talented School Students. Journal of Cognitive Psychology, 8(2), 46-57. Retrieved from. [Link]

Gallagher, S., Smith, S., \& Merrotsy, P. (2013). You turn up the first day and they expect you to come back! Gifted students' perspectives on school and being smart. Gifted and Talented International, 28(1-2), 111-121. [Link]

Gallitto, E., \& Leth-Steensen, C. (2019). Moderating effect of trait emotional intelligence on the relationship between parental nurturance and prosocial behaviour. Journal of adolescence, 74, 113-119. [Link]

Goodman, R. (2001). Psychometric properties of the Strengths and Difficulties Questionnaire. Journal of the American Academy of Child \& Adolescent Psychiatry, 40(11), 1337-1345. [Link]

Goreyshi, M. K., Noohi, S., \& Ajilchi, B. (2013). Effect of combined mastery-cooperative learning on emotional intelligence, self-esteem and academic achievement in grade skipping. Procedia-Social and Behavioral Sciences, 84, 470-474. [Link]

Jafarkhani, Z., Andishmand, V., \& Baghban, N. (2015). Intelligence and newtheories of identifying the gifted. Third International Conference on New Research in Management, Economics and Humanities. [Link]

Jenaabadi, H., Pourghaz, A., \& Shabani, M. (2017). A comparative study of the relationship between basic psychological needs of self-determination and personal adjustment in gifted and normal students. Journal of School Psychology, 6(3), 23-45. doi:10.22098/jsp.2017.583. [Link]

Karnes, F. A., \& Shaunessy, E. (2004). Gifted students with disabilities: Are we finding them?. Gifted Child Today, 27(4), 16-21. [Link]

Kazemihaghighi, N. (2015). Cultural talent and ingenuity: theoretical foundations. Quarterly Journal of Brilliant Talents, 12 (70), 171-151. [Link]

Livarjani, S., Goolmohammadnezhad, G., \& Gasemshahanagi, M. (2009). An investigation of the relationship between gifted and normal female high school students' emotional intelligence and social skills in in Khoy Township in 1388-89. Journal of Instruction and Evaluation, 2(5), 185210. Retrieved from. [Link]

Talaei, E, Hassaneabadi, H. R., Baraparpour, G., Seyed Mirzaei Jahaghi, A., \& Banshi, A. (2018). Enriching students' home learning environment with academic mutation: Comparing mutated groups with nonmutant counterparts. Family and Research Quarterly, 15 (2), 30-7. [Link]

Taklavi, S. (2011). The purpose of the present study was to train mothers in play therapy and investigate its effects on the behavior problems of learning disabled children. An experimental research design was used. A sample of 15 students with learning disability was randomly selected. The mothers of the study sample received 5 sessions of training in play therapy. The mothers also completed Rotter's Behavior Problems Scale. Data were analyzed using the paired t test. The results showed that training. Journal of Learning Disabilities, 1(1), 44-59. doi:jld-1-1-90-7-3. [Link]

Tehranidoust, M., Shahrivar, Z., Pakbaz, B., Rezaei, A., \& Ahmadi, F. (2007). Validity of Farsi Version of 
Strengths and Difficulties Questionnaire (SDQ). Advances in Cognitive Sciences, 8(4), 33-39. Retrieved from. [Link]

Ogurlu, U. (2021). A meta-analytic review of emotional intelligence in gifted individuals: A multilevel analysis. Personality and Individual Differences, 110503. [Link]

Park, G., Lubinski, D., \& Benbow, C. P. (2013). When less is more: Effects of grade skipping on adult STEM productivity among mathematically precocious adolescents. Journal of Educational Psychology, 105(1), 176. [Link]

Prior, S. (2011). Student voice: What do students who are intellectually gifted say they experience and need in the inclusive classroom?. Gifted and Talented International, 26(1-2), 121-129. [Link]

Pfeiffer, S. I. (2013). Lessons learned from working with high-ability students. Gifted Education International, 29(1), 86-97. [Link]

Sayler, M. F., \& Brookshire, W. K. (1993). Social, emotional, and behavioral adjustment of accelerated students, students in gifted classes, and regular students in eighth grade. Gifted Child Quarterly, 37(4), 150-154. [Link]

Shek, D. T., \& Lin, L. (2016). Delinquent behavior in high school students in Hong Kong: sociodemographic, personal, and family determinants. Journal of pediatric and adolescent gynecology, 29(1), S61S71. [Link]

Sherkat, M., Kalantari, M., Azarbayejani, M., \& Abedi, M. R. (2020). The effects of education on spiritual intelligence on students' psychological wellbeing, anxiety, depression, and spiritual intelligence. The Journal Of Psychological Science, 19(88), 483-493. Retrieved from. [Link]

Zee, M., \& Roorda, D. L. (2018). Student-teacher relationships in elementary school: The unique role of shyness, anxiety, and emotional problems. Learning and Individual Differences, 67, 156-166. [Link]

Zhang, R. P., Bai, B. Y., Jiang, S., Yang, S., \& Zhou, Q. (2019). Parenting styles and internet addiction in Chinese adolescents: Conscientiousness as a mediator and teacher support as a moderator. Computers in Human Behavior, 101, 144-150. [Link] 